\title{
Complex Regional Pain Syndrome Type I Induced by Pacemaker Implantation, with a Good Response to Steroids and Neurotropin
}

\author{
Makoto OKada, Kimihiro Suzuki, Toshihiko Hidaka, Tadashi Shinohara, Koji Kataharada, \\ Kunio TAKada, Hisahide TANAKA* and Fumitaka OHSUZU
}

\begin{abstract}
An 84-year-old woman was referred to our hospital because of aches and pain in her left hand and foot. Three months before her symptoms occurred, a pacemaker had been implanted for the treatment of a 2:1 atrioventricular block with bradycardia. In an X-ray examination, prominently decreased bone density was noted in her left fingers and toes. She was diagnosed to have CRPS-I, which was considered to have been induced by the pacemaker implantation. After treatment with methylprednisolone and Neurotropin $^{\circledR}$, her symptoms dramatically improved.

(Internal Medicine 41: 498-501, 2002)
\end{abstract}

Key words: reflex sympathetic dystrophy (RSD), X-ray examination

\section{Introduction}

Complex regional pain syndrome type I (CRPS-I) (conventionally called reflex sympathetic dystrophy: RSD) is a painful disorder that may develop as a disproportionate consequence mainly after a minor trauma (1). This disease generally occurs in those over 50 years old, and both genders are affected equally. The clinical features are severe pain, tenderness and swelling in the distal extremities accompanied with vasomotor instability and trophic changes in the skin and deep tissues $(2,3)$. Various medical treatments (drawing blood, local anesthesia, surgery, cast, etc.) as well as some diseases including stroke and myocardial infarction (1) may induce CRPS-I.

Common complications of a pacemaker implantation, pacemaker pocket infection, generator erosion, electrode displacement, electrode malfunction and pacemaker's syndrome have all been described $(4,5)$. However, CRPS-I has not yet been reported as a complication of pacemaker implantation.
We herein describe a case of CRPS-I associated with pacemaker implantation.

\section{Case Report}

An 84-year-old woman was referred to our hospital from the cardiology department of a nearby hospital in September 2000 , because of aches and pain in her left hand and left foot. She had been in good health until October 1999, when she developed a 2:1 atrioventricular block with bradycardia (heart rate: $30-40$ beats $/ \mathrm{min}$.). In January 2000 , a pacemaker (pacing mode: VVI) was implanted at the nearby hospital. A permanent pacing lead was inserted through the left subclavian vein to be positioned in the right ventricular apex by a venipuncture technique. The lead was then attached to the pulse generator, which was inserted into a subcutaneous pocket below the left clavicle (Fig. 1). After the operation, she was dressed with a chest band and kept at rest in bed for 6 hours. During the bed rest, the left upper extremity was not fixed. Pacemaker pocket neuralgia was not recognized. No failures or malfunctions of the pacing system were observed. In April 2000, she developed aches and pain in her left hand and left foot, and her grip strength in the left hand began to gradually decrease.

On the first physical examination, her height was $150 \mathrm{~cm}$ and weight, $50 \mathrm{~kg}$. She had a clear consciousness. Her left hand and left foot were moderately swollen, and a slight flexion contracture of the left fingers was noted. The joints in her left hand were tender. Allodynia and hyperpathia were also noted. Her left upper and lower distal extremities were more warm and reddish than the right extremities. Thermography was not performed. The grip strength of her right hand and that of left hand were $194 \mathrm{mmHg}$ and $72 \mathrm{mmHg}$ (as measured by a mercury dynamometer), respectively. Neither pain nor tenderness were recognized at the site of the implanted pulse generator. The laboratory data were as follows: the erythrocyte sedimentation rate; $14 \mathrm{~mm} / \mathrm{h}$; white blood cell count, 3,600/ $\mu \mathrm{l}$; hemoglobin, $12.2 \mathrm{~g} / \mathrm{dl}$; platelet count, $23.0 \times 10^{4} / \mu \mathrm{l}$; serum aspartate

From Internal Medicine I, National Defense Medical College, Tokorozawa and *Tokyo Eisei Hospital, Tokyo

Received for publication August 31, 2001; Accepted for publication January 24, 2002

Reprint requests should be addressed to Dr. Makoto Okada, Internal Medicine I, National Defense Medical College, 3-2 Namiki, Tokorozawa, Saitama 3598513. 


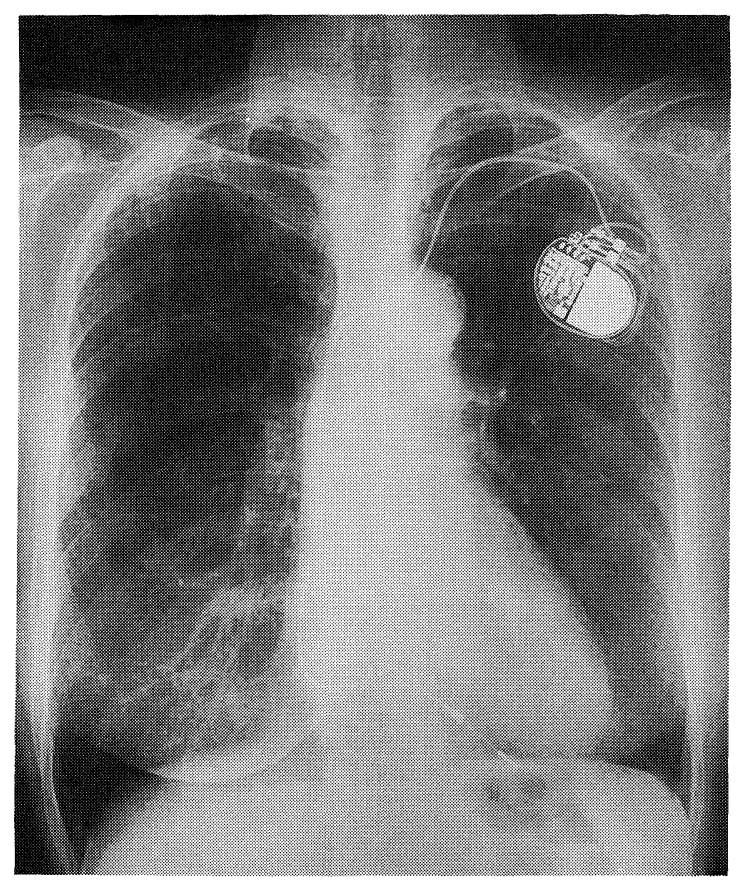

aminotransferase, 24 IU/l; alanine aminotransferase, 13; lactate dehydrogenase, 201; alkaliphosphatase, 239; total protein, $6.6 \mathrm{~g} / \mathrm{dl}$; creatinine, $0.86 \mathrm{mg} / \mathrm{dl}$; total cholesterol, 202; HDLcholesterol, 45.1; blood glucose, 103; C-reactive protein, $<0.3$; serum immunoglobulin $\mathrm{G}, 1,150 ; \mathrm{CH}_{50}, 52.1 \mathrm{U} / \mathrm{ml}$; anti-agal IgG antibody $\left(\mathrm{CA}^{-\mathrm{RF}^{\circledast}}\right)<3.1 \mathrm{AU} / \mathrm{ml}$, antinuclear antibody titers, 1:40; anti-double stranded DNA antibodies, $<1 \mathrm{IU} / \mathrm{ml}$; IgGanti cardiolipin antibodies, 8 (normal, $<10$ ); anti-CL $\beta_{2}$ GPI, $<0.7$ $\mathrm{U} / \mathrm{ml}$ ( $\leqq 3.5$ ); lupus anticoagulant, $1.1(<1.3)$. On brain computed tomography $(\mathrm{CT})$, several minute lacunar infarctions were noted in the bilateral white matter. In an X-ray examination, a prominently decreased bone density and a loss of trabeculae were noted in her left fingers (Fig. 2) and toes. Bone scintigraphy was not done. According to the criteria devised by Gibbons and Wilson (6), she was diagnosed to have CRPS-I. This disease was considered to be associated with the pacemaker implantation, because there were no other episodes that could

Figure 1. Chest roentgenogram. A pulse generator was noted below the left clavicle, and the electrode was correctly lodged.
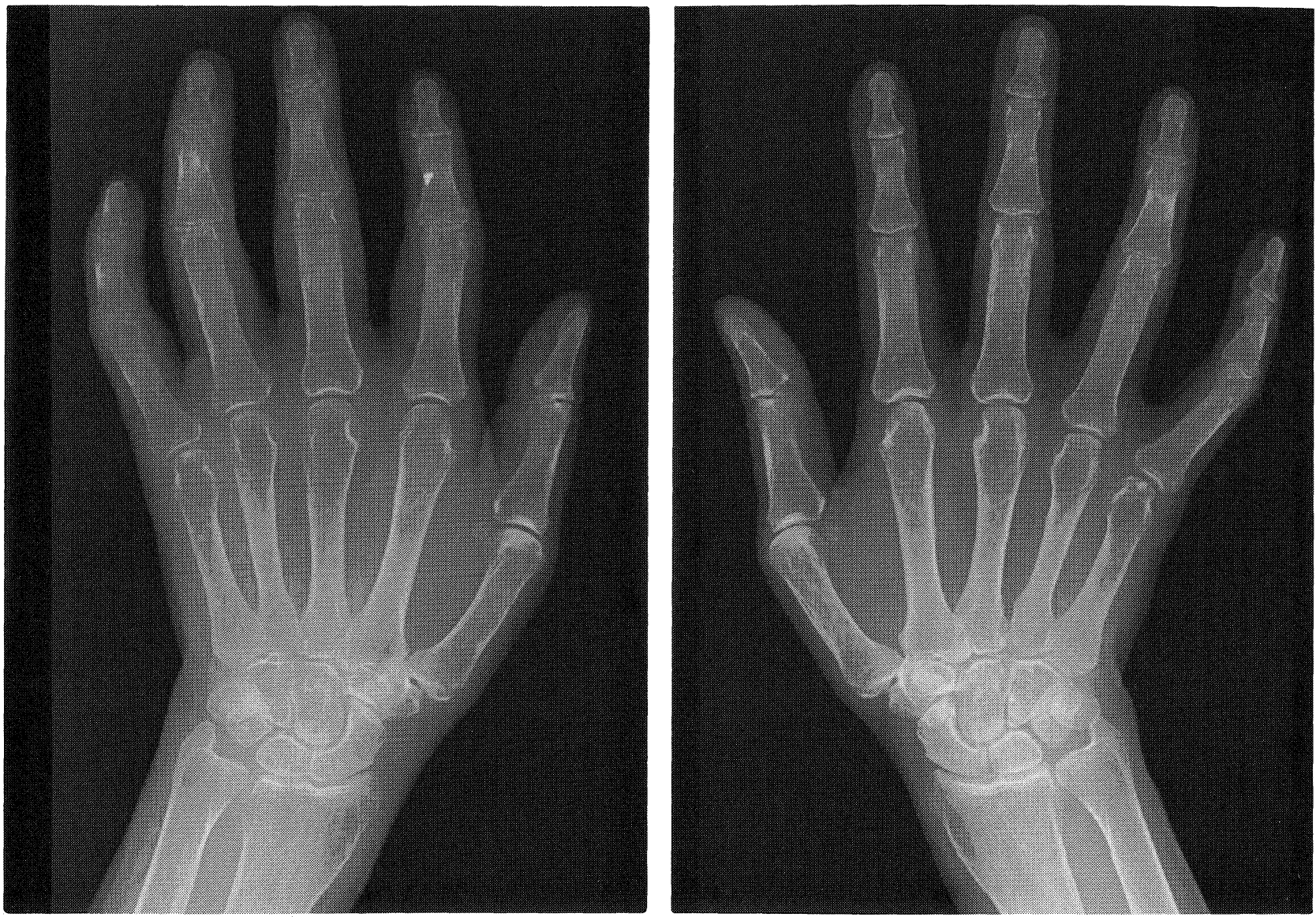

Figure 2. Roentgenograms of the bilateral hands of this patient. Prominently decreased bone density and loss of trabeculae were observed in the patient's left fingers. Swelling of soft tissues of the left hand was also noted. 

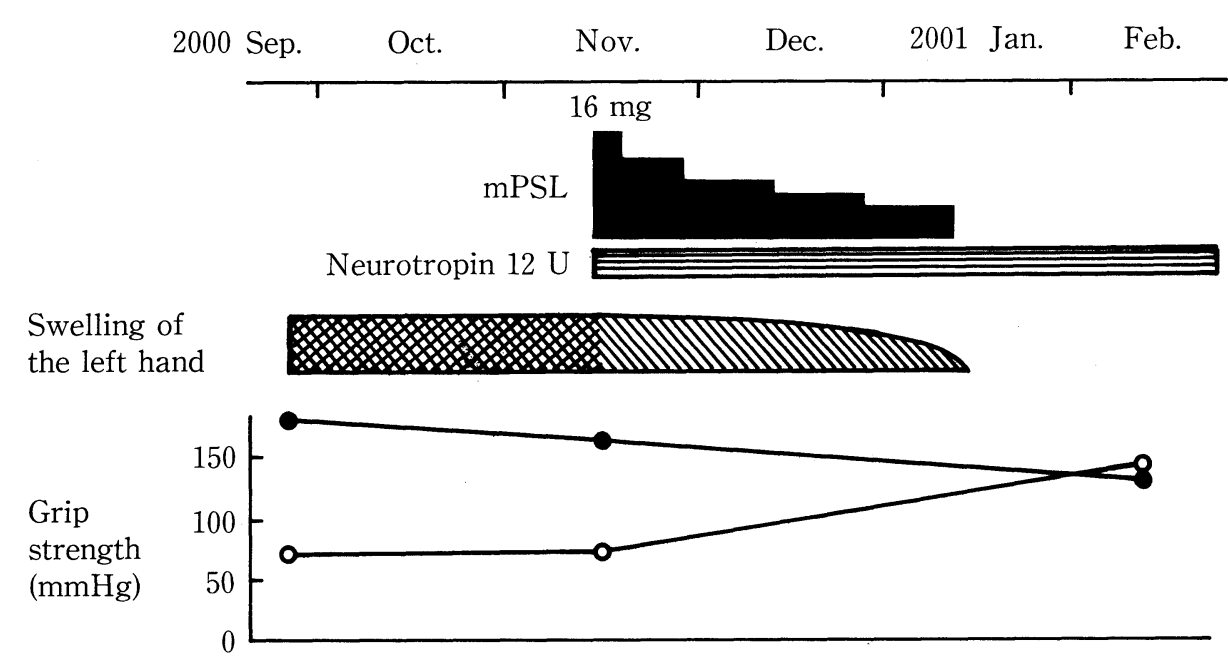

Figure 3. The clinical course and therapies for complex regional pain syndrome type $I$. mPSL: methylprednisolone, $\bigcirc$ : left hand, $\bigcirc$ : right hand.

have triggered CRPS-I, such as an injury or stroke. After the administration of methylprednisolone (initial dose: $16 \mathrm{mg} /$ day) and Neurotropin ${ }^{\circledR} 12 \mathrm{U} /$ day, the symptoms in her left hand and left foot were dramatically improved (Fig. 3). The administration of methylprednisolone was gradually tapered until it was no longer needed by 2 months after the start of administration.

\section{Discussion}

The pathogenesis of CRPS-I is considered to be as follows: a continuous stimulation of the primary afferent axons in the affected lesion subsequently leads to an abnormal state of the primary afferent neurons and to a distorted processing of information in the spinal cord. As a consequence of this abnormal central state, the activity in the sympathetic (vasomotor and sudomotor) supply to the affected extremity becomes distorted (2). According to this theory, in this case, the continuous stimulation of the afferent sensory nerves around the implanted pacemaker system might have been conveyed to the spinal cord, thus evoking an abnormal reaction of the sympathetic nervous system of the collateral extremities.

Recent reports suggested that autonomic disturbances were not related to the pathogenesis of CRPS-I $(7,8)$. Veldman et al analyzed signs and symptoms in 829 CRPS-I patients, and proposed that CRPS-I was caused by exaggerated regional inflammatory response to injury or operation (7). This hypothesis might be partially applicable in the present case. However, the site of the implanted pacemaker system differed from the site where the symptoms of CRPS-I were noted.

Numerous reports on the efficacy of corticosteroid therapy for CRPS-I have been published (7, 9-13). Kozin et al described that systemic corticosteroid therapy has been proven to be a highly effective mode of treatment for up to 90 percent of the patients with the CRPS-I (3). These responses were not affected by the duration of symptoms prior to corticosteroid ad- ministration. In fact, in this case, steroid proved to be an effective treatment for CRPS-I even when it was administered as late as 7 months after the onset of symptoms. Another report described a more than $75 \%$ clinical improvement (11). The mechanism of steroid efficacy for CRPS-I is speculated to be due to a reduction in the permeability of the blood capillaries by stabilizing the cell membranes (especially, in nerve endings), along with an alleviation of inflammatory pain (14). The reported initial doses of prednisolone were variable from 10 $\mathrm{mg}$ to $60(3,10-12)$. The present case was initially treated with $16 \mathrm{mg}$ methylprednisolone, which corresponded to $20 \mathrm{mg}$ prednisolone, and successfully tapered without recurrence.

Neurotropin ${ }^{\circledR}$ is a biological material obtained from inflamed rabbit skin inoculated with the vaccinia virus which is widely used clinically as an effective agent for a chronic pain syndrome. Neurotropin ${ }^{\circledast}$ produces analgesia by the activation of a descending pain inhibitory system (15). The usefulness of Neurotropin ${ }^{\circledR}$ for CRPS-I has also been reported $(15,16)$. The ameliorating effects of Neurotropin ${ }^{\circledR}$ in various pain syndromes may be related to its ability to inhibit the activation of the kallikrein-kinin cascade and consequently prevent the formation of bradykinin (16). Along with corticosteroids, it is considered to effectively ameliorate the symptoms of CRPS-I. The National Institute of Health in the USA has conducted a study (Protocol number: 00-D-020) since 2000 to reveal whether or not Neurotropin ${ }^{\circledR}$ can effectively treat complex regional pain syndrome.

\section{References}

1) Wasner G, Schattschneider J, Heckmann K, Maier C, Baron R. Vascular abnormalities in reflex sympathetic dystrophy (CRPS I): mechanisms and diagnostic value. Brain 124: 587-599, 2001.

2) Blumberg $\mathrm{H}$, Janig W. Changes of reflexes in vasoconstrictor neurons supplying the cat hindlimb following chronic nerve lesions: a model for studying mechanisms of reflex sympathetic dystrophy? J Auton Nerv Syst 


\section{CRPS-I Due to Pacemaker Implantation}

7: 399-411, 1983.

3) Kozin F, Ryan LM, Carerra GF, Soin JS, Wortmann RL. The reflex sympathetic dystrophy syndrome (RSDS). III. Scintigraphic studies, further evidence for the therapeutic efficacy of systemic corticosteroids, and proposed diagnostic criteria. Am J Med 70: 23-30, 1981.

4) Aggarwal RK, Connelly DT, Ray SG, Ball J, Charles RG. Early complications of permanent pacemaker implantation: no difference between dual and single chamber systems. Br Heart J 73: 571-575, 1995.

5) Harcombe AA, Newell SA, Ludman PF, et al. Late complications following permanent pacemaker implantation or elective unit replacement. Heart 80: 240-244, 1998.

6) Gibbons JJ, Wilson PR. RSD score: criteria for the diagnosis of reflex sympathetic dystrophy and causalgia. Clin J Pain 8: 260-263, 1992.

7) Veldman PH, Reynen HM, Arntz IE, Goris RJ. Signs and symptoms of reflex sympathetic dystrophy: prospective study of 829 patients. Lancet 342: 1012-1016, 1993.

8) Drummond PD, Finch PM, Smythe GA. Reflex sympathetic dystrophy: the significance of differing plasma catecholamine concentrations in affected and unaffected limbs. Brain 114: 2025-2036, 1991.

9) Glick EN. Reflex dystrophy (algoneurodystrophy): results of treatment by corticosteroids. Rheumatol Rehabil 12: 84-88, 1973.

10) Mowat AG. Treatment of the shoulder-hand syndrome with corticosteroids. Ann Rheum Dis 33: 120-123, 1974.

11) Christensen $K$, Jensen EM, Noer I. The reflex dystrophy syndrome response to treatment with systemic corticosteroids. Acta Chir Scand 148: 653-655, 1982.

12) Hidaka T, Suzuki K, Hara M, Kawagoe M, Nakamura H. Spontaneous reflex sympathetic dystrophy (Sudeck's atrophy) syndrome associated with idiopathic thrombocytopenia. J Rheumatol 19: 989-991, 1992.

13) Braus DF, Krauss JK, Strobel J. The shoulder-hand syndrome after stroke: a prospective clinical trial. Ann Neurol 36: 728-733, 1994.

14) Koman LA, Poehling GG. Reflex sympathetic dystrophy. Operative nerve repair and reconstruction, Gelberman RH (ed), Lippincott, Philadelphia, 1991: 1497-1523.

15) Toda K, Muneshige H, Ikuta Y. Antinociceptive effects of neurotropin in a rat model of painful peripheral mononeuropathy. Life Sci 62: 913-921, 1998.

16) Nishikawa K, Reddigari SR, Silverberg M, et al. Effect of Neurotropin on the activation of the plasma kallikrein-kinin system. Biochem Pharmacol 43: 1361-1369, 1992. 